\title{
Predictors of 30- and 90-Day COPD Exacerbation Readmission: A Prospective Cohort Study
}

\author{
Jaber S Alqahtani $\mathbb{B D}^{1,2}$ \\ Yousef S Aldabayan ${ }^{3}$ \\ Abdulelah M Aldhahir ${ }^{4}$ \\ Ahmad M Al Rajeh (D) ${ }^{3}$ \\ Swapna Mandal ${ }^{1,5, *}$ \\ John R Hurst $\mathbb{D}^{1,5, *}$ \\ 'UCL Respiratory, University College \\ London, London, UK; ${ }^{2}$ Department of \\ Respiratory Care, Prince Sultan Military \\ College of Health Sciences, Dammam, \\ Saudi Arabia; ${ }^{3}$ Respiratory Care \\ Department, College of Applied Medical \\ Sciences, King Faisal University, Al-Hasa, \\ Saudi Arabia; ${ }^{4}$ Respiratory Care \\ Department, Faculty of Applied Medical \\ Sciences, Jazan University, Jazan, Saudi \\ Arabia; ${ }^{5}$ Respiratory Medicine, Royal \\ Free London NHS Foundation Trust, \\ London, UK
}

*These authors contributed equally to this work
Correspondence: Jaber S Alqahtani UCL Respiratory, University College London, Rowland Hill Street, London, NW3 2PF, UK

Email Alqahtani-Jaber@hotmail.com
Background: Readmission following COPD exacerbation is a common and challenging clinical problem. New approaches to predicting readmissions are required to help mitigate risk and develop novel interventions.

Methods: We conducted a prospective cohort study in 82 COPD patients admitted due to an exacerbation of COPD. Lung function measures [spirometry, forced oscillation technique (FOT) indices and peak inspiratory flow rate (PIFR)], inflammatory biomarkers and patientreported outcomes including previous exacerbation history, breathlessness, quality of life and frailty were measured at admission and discharge. We prospectively followed patients for 30 and 90 days to identify predictors for readmission.

Results: The readmission rate within 30 days was 38\%, and 56\% within 90 days. Previous exacerbations, higher COPD Assessment Test score at discharge, frailty, reduced PIFR and increased length of stay were significantly associated with 30-day readmission. PIFR at discharge and frailty had the highest predictive ability for 30-day readmission using area under receiver operating characteristic curves (AUC 0.86, 95\% CI 0.78-0.95, p < 0.001 and AUC $0.81,95 \%$ CI $0.71-0.90, \mathrm{p}<0.001$, respectively). Ninety-day readmissions were significantly associated with previous exacerbations and hospitalisations, higher CAT score at discharge, frailty, depression, lower PIFR and greater expiratory flow limitation (EFL) in the supine position. The best predictive variable in multivariable analysis for both 30 - and 90-day readmission was PIFR at discharge.

Conclusion: PIFR, CAT score, frailty, and EFL were found to be associated with 30- and 90-day readmission following COPD exacerbation. These findings help identify those at highest risk and to optimise care prior to discharge.

Keywords: COPD, exacerbation, admission, readmission, predictor, risk factor, PIFR, frailty, EFL

\section{Introduction}

Approximately 3.2 million global deaths occur each year due to chronic obstructive pulmonary disease (COPD), ${ }^{1}$ in which exacerbations of COPD remain a prevailing cause. ${ }^{2}$ Exacerbations requiring hospitalisation are associated with high mortality and mortality risk is increased with higher exacerbation frequencies. ${ }^{3}$ For COPD patients surviving hospitalisation due to COPD exacerbations, readmission is a major clinical problem. COPD hospital readmissions contribute to a clinical and economic burden on patients and society. ${ }^{4}$ Identifying and mitigating risk factors for readmission is, therefore, essential. ${ }^{5,6}$

A recent systematic review and meta-analysis of nearly four million COPD patients found that the all-cause readmission rate at 30 days ranged from $9 \%$ to 
$26 \%$, and from $18 \%$ to $39 \%$ at 90 days. $^{7}$ The commonest risk factors for all-cause readmissions within 30 and 90 days were comorbidities, previous exacerbations and hospitalisations, and increased length of stay during the initial admission. ${ }^{7}$ The European COPD Audit reported higher in-hospital mortality in those readmitted within 90 days compared to those who do not get readmitted (13.4\% vs $2.3 \%)^{8}$

Further investigations are needed to better understand the reasons for readmission and recurrence of exacerbations, and to identify better approaches to avoid readmissions. Such uncertainties have been identified as a top-ten research priority in a recent patient-clinician research prioritisation exercise for COPD exacerbations. ${ }^{9}$ Despite global policy makers' initiatives to apply financial penalties to hospitals with higher readmission rates, limited impact on changing readmission has been observed. ${ }^{10}$ Few prospective studies have been conducted in this important area, which limits assessment of markers that might be used to predict early readmissions. ${ }^{7}$ Hence, there is an increasing need for prospective studies to identify novel biomarkers or phenotypes of patients at greater risk of readmission, ${ }^{11,12}$ ideally identifying variables that can be modified through intervention. Early identification of patients at higher risk of readmission and providing timely treatment could minimise this risk. Therefore, our study aimed to prospectively identify risk factors of COPD readmission within 30 and 90 days and find potential biomarkers that can be modified to improve readmission burden.

\section{Methods}

This was a single centre prospective cohort study conducted on respiratory wards at the Royal Free Hospital London NHS Foundation Trust, UK. Ethical approval was obtained from the health research authority (HRA) and Health and Care Research Wales (HCRW) (reference 19/ $\mathrm{EM} / 0080$ ). All patients provided informed consent to participate in this study and this study complied with the Declaration of Helsinki. The trial was registered at ClinicalTrials.gov (NCT number): NCT04024735. ${ }^{13}$

\section{Recruitment of Participants}

We consecutively approached patients admitted to due to a COPD exacerbation. We identified patients from admission lists that were updated every 24 hours. Over a period of ten months from May 2019 to March 2020, patients with a confirmed diagnosis of COPD (post-bronchodilator $\mathrm{FEV}_{1} / \mathrm{FVC}<0.70$ and appropriate exposure history) and being managed for an exacerbation were recruited. In March 2020 study recruitment was stopped due to coronavirus pandemic restrictions. We excluded any patient with a predominant history of asthma or bronchiectasis, patients with mental health disorders preventing compliance with the trial protocol and those in whom an initial diagnosis of COPD exacerbation was revised to an alternative at a later phase of their admission.

\section{Measurements}

Demographic data and a complete medical history including smoking and exacerbation history, and medication were collected. Patient-reported outcomes were measured, including assessment of dyspnoea (modified Medical Research Council (mMRC) score $^{14}$ COPD Assessment Test (CAT) ${ }^{15}$ anxiety and depression (Hospital Anxiety and Depression Scale, HADS ${ }^{16}$ and frailty using the Reported Edmonton Frail Scale (REFS). ${ }^{17}$ For each patient, we collated blood results to determine inflammatory biomarkers.

Quality assured spirometry using ndd EasyOne ${ }^{\circledR}$ Air (ndd, Zurich, Switzerland) was performed according to American Thoracic Society (ATS)/European Respiratory Society (ERS) criteria. ${ }^{18}$

A Forced Oscillation Technique (FOT) device (ResmonPro; ResTech, Milan, Italy) was used to measure patients' respiratory impedance: resistance (Rrs) and reactance (Xrs) at 5Hz. ${ }^{19}$ Expiratory Flow Limitation (EFL) was measured by within breath difference in reactance at $5 \mathrm{~Hz}\left(\Delta \mathrm{Xrs}_{5 \mathrm{~Hz}}\right)$ to detect flow limited breaths. ${ }^{20}$ This test was conducted according to standard recommendations. ${ }^{19}$ In brief, patients were instructed to be in a sitting position with the head in a neutral or slightly extended position to perform the test. The patients' cheeks and base of the mouth were firmly supported using both hands and a nose clip was placed to eliminate leak. Each patient was instructed to breathe in and out normally for 10-20 breaths into the ResmonPro. FOT measurements were also taken in the supine position.

Peak inspiratory flow rate (PIFR) was measured using the InCheckTM DIAL (Clement Clarke International Ltd, Harlow, UK and Alliance Tech Medical). This tool is well validated and can measure inspiratory flow rates between 15 and $120 \mathrm{~L} / \mathrm{min}^{21,22}$ Suboptimal PIFR was defined as below $60 \mathrm{~L} / \mathrm{min}$ and the apparatus was set to simulate resistance of the DISKUS ${ }^{\circledR}$ Dry powder inhaler (DPI), a commonly used DPI device.

All the above measurements were conducted at a recruitment assessment within the first 48 hours of 
admission, and within two days before discharge from hospital.

\section{Follow-Up}

At discharge, patients were followed-up at 30 and 90 days to capture hospital readmission. We used the hospital dataset and follow-up calls to confirm information about readmissions within the follow-up period. Readmission was defined as any emergency (non-elective) readmission to hospital within the specified follow-up time.

\section{Statistical Analysis}

Data were inspected using histograms to look for outliers and tested for normality using a Kolmogorov-Smirnov test. If normally distributed (parametric), data were expressed as mean and standard deviation (SD) and if not normally distributed data were expressed as median and inter-quartile range (IQR) (non-parametric) as appropriate. Categorical variables were compared using the $\chi 2$ test or the Fisher exact test. A univariate analysis was performed to identify variables associated with 30- and 90day readmission. A multivariable logistic analysis was applied in which readmission at 30 and 90 days were the dependent variables, whilst the independent variables were identified from the univariate analysis to be associated with 30- and 90-days readmission. For other comparisons, Wilcoxon signed-rank was used for non-parametric paired data and a paired $T$-test was used for parametric data.

Relationships between variables were analysed using Spearman's rank correlation coefficient test for nonparametric variables and for normally distributed variables we used the Pearson correlation coefficient.

A receiver operating characteristic (ROC) curve was constructed to assess how significant factors in univariate logistic regression predicted readmission. We found the optimum cut-off point for the best predictors (AUC $>0.80$ ) using the point on the curve with minimum distance from the left-upper corner of the unit square. We calculated the positive predictive value (PPV) and negative predictive value (NPV) for each cut-off. We analysed our data using the software Statistical Package for the Social Sciences (SPSS), Version 25.

\section{Power Calculation}

Statistical advice was sought about our sample size and data analysis from the Biostatistics Group at the UCL Joint Research Office (JRO). It was recommended to have 10 readmission events as a minimum number of events per variable in a multivariable method of analysis, as has been previously reported in the literature..$^{23,24}$ In our study, readmission was the event of interest, therefore having 30-40 readmitted patients would allow us to examine 3 to 4 variables in a logistic regression model. As per the National COPD Audit in the UK, the national readmission rate for COPD patients is $24 \%$ within 30 days. $^{6}$ Accordingly, we originally aimed to recruit 125 to 166 patients in order to have 30 to 40 readmissions.

\section{Results}

\section{Baseline Characteristics}

We approached 152 patients admitted with COPD exacerbation. A total of 129 with a confirmed diagnosis of COPD were recruited; 23 patients declined to participate. A total of 47 were excluded due to the reasons described in Figure 1. 82 patients were recruited and followed-up to 90 days. There was a slight predominance of female patients $(51 \%)$ and the group as a whole had a mean (SD) age of $71 \pm 10.4$ years and smoking history of 42 (29-56) pack years (Table 1). The readmission rate within 30 days was $38 \%$ (31/82), and 56\% within 90 days (46/ $82)$. The average time to readmission within 30 and 90 days was $11(5-22)$ and $22(10-57)$ days respectively. Table 1 describes the baseline characteristics of the patients categorised into those who had and had not been readmitted within 30 days. The reasons for readmission within 30 and 90 days were most commonly COPDrelated, 52 and 55\% respectively. Patients readmitted within 30 days had experienced more exacerbations [3 (2-5) vs 2 (1-4), p=0.01], and hospitalisations [2 (1-4) vs $1(0-2), p=0.006]$ in the previous 12 months compared to those who were not readmitted. The proportion of patients who received a "care bundle" prior to discharge (smoking cessation support, inhaler technique check, referral to pulmonary rehabilitation and follow-up arrangements) was $85 \%$.

\section{Predictors of 30-Day Readmission}

Length of stay was statistically different between the groups such that those who were readmitted within 30 days had a longer length of stay in hospital [8 (5-14) vs 6 (4-10) days, $p=0.03$ ]. At admission, readmitted patients had greater anxiety and depression [HADS: 12 (8-14) vs 9.5 (6-13), $\mathrm{p}=0.02]$ and frailty [REFS 12 (11-14) vs 10 $(8-11), p=0.001]$ scores compared to those with no readmission. There were no significant differences between 


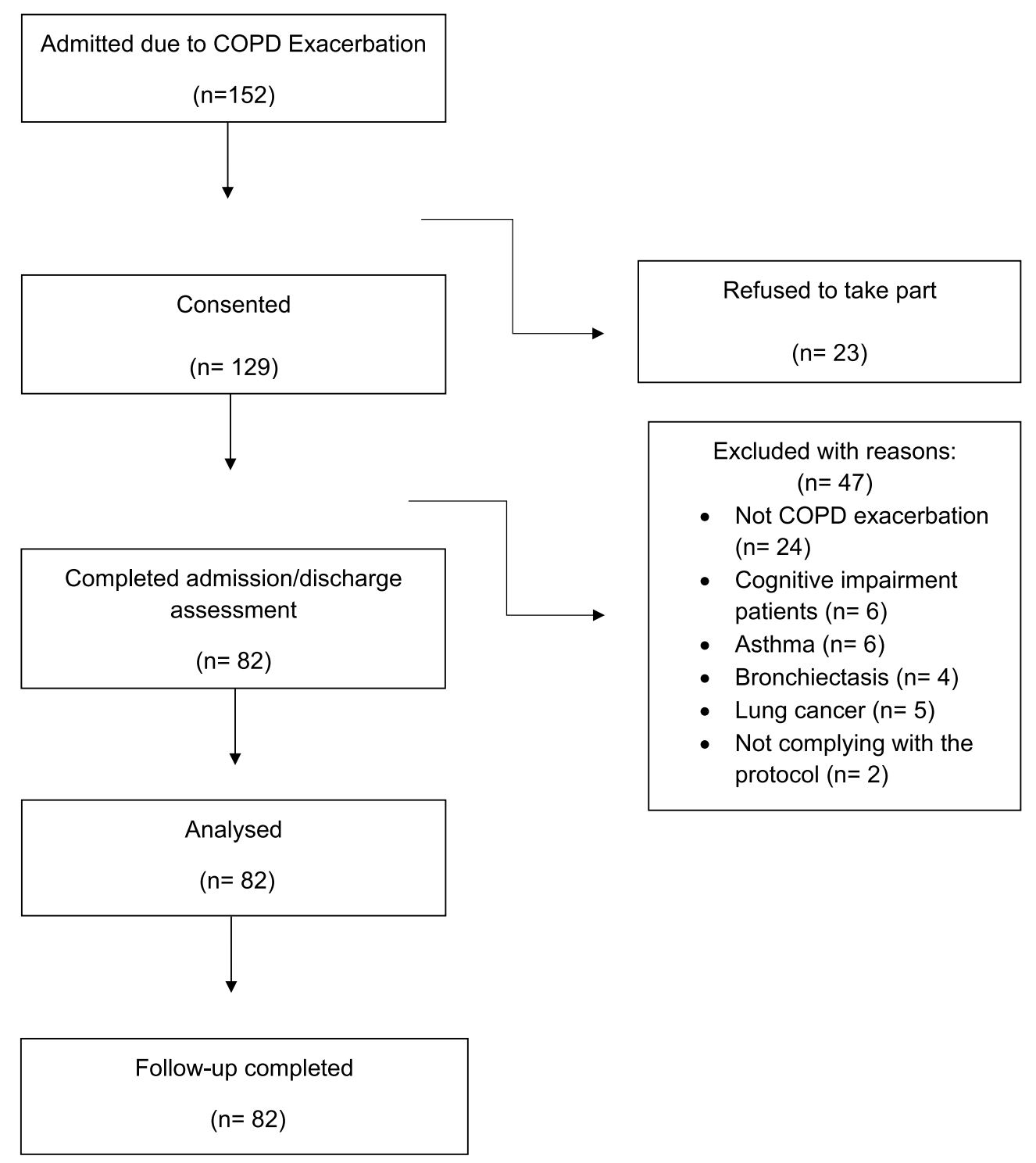

Figure I Consort diagram.

groups in spirometry and FOT values at the recruitment assessment (Table 1). However, there was a statistically significant difference in PIFR [50 (40-60) vs 80 (55-90) $\mathrm{L} / \mathrm{m}, \mathrm{p}=0.001]$ between groups at admission. Sub-optimal PIFR $(<60 / \mathrm{min})$ was seen in $46 \%(38 / 82)$ at admission and $40 \%(33 / 82)$ at discharge.

\section{Changes from Admission to Discharge Between Both Groups}

We assessed the change from admission to discharge in lung function parameters and blood biomarkers between those who were and were not readmitted at 30 days (Table 2). There were no significant differences within and between groups in FOT values. There was no improvement in the PIFR from admission to discharge in readmitted patients, while we found a statistically significant improvement in those with no readmission $5(-10$, 8.5) vs $12.5(5,20), \mathrm{L} / \mathrm{min}, \mathrm{p}=0.001]$. There was a statistically significant change in CAT score between those readmitted and not $[-8(-12,-3)$ vs $-11(-14,-7)$, $\mathrm{p}=0.001]$, respectively.

\section{Factors Associated with the Readmission Within 30 Days}

In univariate logistic-regression analysis, we assessed factors associated with 30-day readmission following exacerbation, using all the variables we found to be significantly different between the two groups. The best predictor of 
Table I Characteristics of the Index Admission Between Those with and without 30-Day Readmission. Variables Measured at the Admission Assessment

\begin{tabular}{|c|c|c|c|c|}
\hline Characteristics & All Patients $(n=82)$ & $\begin{array}{l}\text { Patients Readmitted Within } \\
30 \text { Days }(n=31)\end{array}$ & $\begin{array}{l}\text { Patients Who Were Not Readmitted } \\
\text { Within } 30 \text { Days }(n=51)\end{array}$ & $P$ value \\
\hline Male & $40(49 \%)$ & $18(58 \%)$ & $22(43 \%)$ & 0.19 \\
\hline Female & $42(51 \%)$ & $13(42 \%)$ & $29(57 \%)$ & \\
\hline Age (years) & $71 \pm 10.4$ & $71 \pm 10$ & $71.4 \pm 11$ & 0.85 \\
\hline BMI (kg/m2) & $24(20-29)$ & $23(20-28)$ & $25(19-30)$ & 0.59 \\
\hline Current smoker & $24(29 \%)$ & $7(23 \%)$ & $17(33 \%)$ & 0.30 \\
\hline Ex-smoker & 58 (71\%) & $24(77 \%)$ & $34(67 \%)$ & \\
\hline Smoking history (Pack Years) & $42(29-56)$ & $42(27-63)$ & $42(29-54)$ & 0.50 \\
\hline Living alone at home & $39(48 \%)$ & $16(52 \%)$ & $23(46 \%)$ & 0.60 \\
\hline $\mathrm{FEV}_{\text {। }}(\mathrm{L})$ & $0.90 \pm 0.34$ & $0.90 \pm 0.35$ & $0.85 \pm 0.34$ & 0.60 \\
\hline $\mathrm{FEV}_{1} \%$ & $34.3 \pm 12.4$ & $34 \pm 11$ & $35 \pm 13$ & 0.67 \\
\hline FVC (L) & $2.2 \pm 2.3$ & $2.2(1.7-2.5)$ & $1.4(2-2.4)$ & 0.22 \\
\hline FVC \% & $61 \pm 16.7$ & $61 \pm 17$ & $61 \pm 16.6$ & 0.98 \\
\hline $\mathrm{FEV}_{1} / \mathrm{FVC}(\%)$ & $43.5 \pm 11$ & $42 \pm 11$ & $44 \pm 11$ & 0.56 \\
\hline IC (L) & $1.3(1-1.8)$ & $1.40(1-1.7)$ & $1.20(1-2)$ & 0.77 \\
\hline PIFR (L/min) & $60(50-85)$ & $50(40-60)$ & $80(55-90)$ & 0.001 \\
\hline $\begin{array}{l}\Delta \mathrm{Xrs}_{5 \mathrm{~Hz}} \text { at upright position } \\
{[\mathrm{cmH} 2 \mathrm{O} /(\mathrm{L} / \mathrm{s})]}\end{array}$ & $2.1(0.4-5.1)$ & $1.7(0.2-4.7))$ & $2.2(0.50-5)$ & 0.60 \\
\hline FL\% at upright position & $20(0-9 \mid)$ & $20(0-90)$ & 2- (0-93) & 0.98 \\
\hline $\begin{array}{l}\Delta \mathrm{Xrs}_{5 \mathrm{~Hz}} \text { at supine position } \\
{[\mathrm{cmH} 2 \mathrm{O} /(\mathrm{L} / \mathrm{s})]}\end{array}$ & $3(0.9-7)$ & $2.6(1.7-8)$ & $3(0.8-7)$ & 0.73 \\
\hline FL\% at Supine position & $50(12-100)$ & $40(27-90)$ & $60(7-100)$ & 0.92 \\
\hline $\begin{array}{l}\mathrm{Rrs}_{5 \mathrm{~Hz}} \text { at upright position }[\mathrm{cmH} 2 \mathrm{O} / \\
(\mathrm{L} / \mathrm{s})]\end{array}$ & $4.7(3.2-6.2)$ & $4.8(3-6.3)$ & $4.8(3.45-6.2)$ & 0.53 \\
\hline $\begin{array}{l}\mathrm{Rrs}_{5 \mathrm{~Hz}} \text { at supine position }[\mathrm{cmH} 2 \mathrm{O} / \\
(\mathrm{L} / \mathrm{s})]\end{array}$ & $5.3(3.7-7.2)$ & $5.5(3.5-6.6)$ & $5.7(3.8-7.4)$ & 0.58 \\
\hline $\begin{array}{l}\text { Number of Exacerbations (within } \\
\text { past } 12 \text { months) }\end{array}$ & $2(1-4)$ & $3(2-5)$ & $2(I-4)$ & 0.01 \\
\hline $\begin{array}{l}\text { Number of hospitalised } \\
\text { exacerbations ( }<12 \text { months) }\end{array}$ & $2(1-3)$ & $2(I-4)$ & I (0-2) & 0.006 \\
\hline $\begin{array}{l}\text { Pulmonary rehabilitation }(<12 \\
\text { months) }\end{array}$ & $28(34 \%)$ & $13(42 \%)$ & $15(29 \%)$ & 0.24 \\
\hline Flu Vaccination (<12 months) & $60(73 \%)$ & $24(77 \%)$ & $36(71 \%)$ & 0.50 \\
\hline Pneumonia Vaccination (<10 years) & $26(32 \%)$ & $13(42 \%)$ & $13(26 \%)$ & 0.12 \\
\hline DECAF Score & $2(1-2)$ & $1.7 \pm 1$ & $1.6 \pm 0.9$ & 0.70 \\
\hline ICS & $50(61 \%)$ & $21(68 \%)$ & $29(57 \%)$ & 0.32 \\
\hline LAMA & $35(43 \%)$ & $15(49 \%)$ & $20(39 \%)$ & 0.41 \\
\hline LABA & $4(5 \%)$ & $2(7 \%)$ & $2(4 \%)$ & 0.60 \\
\hline
\end{tabular}


Table I (Continued).

\begin{tabular}{|c|c|c|c|c|}
\hline Characteristics & All Patients $(n=82)$ & $\begin{array}{l}\text { Patients Readmitted Within } \\
30 \text { Days }(n=31)\end{array}$ & $\begin{array}{l}\text { Patients Who Were Not Readmitted } \\
\text { Within } 30 \text { Days }(n=51)\end{array}$ & $P$ value \\
\hline Length of stay in days & $7(4-10.3)$ & $8(5-14)$ & $6(4-10)$ & 0.03 \\
\hline CAT Score & $31(27.7-34)$ & $31(28-36)$ & $32(27-33)$ & 0.50 \\
\hline $\mathrm{mMRC}$ & $4(3.7-4)$ & $4(3-4)$ & $4(4-4)$ & 0.80 \\
\hline Frailty (REFS) & $10(9-12.2)$ & $12(11-14)$ & $10(8-11)$ & 0.001 \\
\hline Depression (HADS) & II (7-14) & $12(8-14)$ & $9.5(6-13)$ & 0.02 \\
\hline Anxiety (HADS) & $9(6.7-11)$ & $10(7-11)$ & $9(6-11)$ & 0.33 \\
\hline WBC (10^9/L) & $10.6(7.9-14.5)$ & $10.5(7-14)$ & $10.7(9-15)$ & 0.50 \\
\hline Eosinophils (10^9/L) & $0.07(0.02-0.24)$ & $0.07(0.03-0.4)$ & $0.06(0.01-0.2)$ & 0.30 \\
\hline Neutrophils (10^9/L) & $8(5.1-11.6)$ & $7.3(5-10.4)$ & $8.2(6-12.3)$ & 0.24 \\
\hline $\mathrm{CRP}(\mathrm{mg} / \mathrm{L})$ & $20(6-62)$ & $30(4-75)$ & $19(7.4-5.5)$ & 0.80 \\
\hline eGFR $\mathrm{mL} / \mathrm{min}$ & $85(65-90)$ & $90(66-90)$ & $78(60-90)$ & 0.25 \\
\hline Charlson Comorbidity Index & $4.3 \pm 1.6$ & $4.4 \pm 1.6$ & $4.2 \pm 1.5$ & 0.71 \\
\hline Systemic hypertension & $32(39 \%)$ & $12(39 \%)$ & $20(40 \%)$ & 0.10 \\
\hline Hyperlipidaemia & $11(13 \%)$ & $6(55 \%)$ & $5(45 \%)$ & 0.22 \\
\hline Atrial Fibrillation & $19(23 \%)$ & $6(19 \%)$ & $13(26 \%)$ & 0.52 \\
\hline Heart failure & $13(16 \%)$ & $6(19 \%)$ & $7(14 \%)$ & 0.50 \\
\hline Chronic kidney disease & $13(16 \%)$ & $5(16 \%)$ & $8(16 \%)$ & 0.95 \\
\hline Home oxygen & 7 (9\%) & $2(6.5 \%)$ & $5(10 \%)$ & 0.60 \\
\hline Home NIV & 7 (9\%) & $2(6.5 \%)$ & $5(10 \%)$ & 0.60 \\
\hline
\end{tabular}

Note: Data are presented as $n(\%)$, mean \pm SD or median (IQR).

Abbreviations: BMI, body mass index; CAT, COPD Assessment Test; CRP, C-reactive protein; DECAF, Dyspnoea, Eosinopenia, Consolidation, Acidaemia and Atrial Fibrillation; eGFR, estimated glomerular filtration rate; HAD, Hospital Anxiety and Depression Scale; ICS, inhaled corticosteroid; LABA, long-acting $\beta$-agonist; LAMA, longacting muscarinic antagonist; mMRC, modified Medical Research Council dyspnoea scale; REFS, Reported Edmonton Frail Scale; WBC, white blood cell; NIV, noninvasive ventilation.

readmission within 30 days was the frailty score (odds ratio, $1.72 ; 95 \%$ confidence interval $[\mathrm{CI}], 1.32$ to 2.29 ; $\mathrm{P}<0.001$ ). Table 3 shows the other variables associated with 30-day readmission.

We found that PIFR at discharge and frailty score values had the highest predictive ability on 30-day readmission (AUC $0.86,95 \%$ CI 0.78 to $0.95, \mathrm{p}<0.001$ and AUC $0.81,95 \%$ CI 0.71 to $0.90, \mathrm{p}<0.001$, respectively) (Figure 2). This indicates an excellent ability to predict readmission, defined as $A U C \geq 0.80$. The highest AUC for CAT score was found when measured at discharge (AUC $0.68,95 \%$ CI 0.55 to $0.81, p=0.006$ ). The ROC results of the other variables are presented in Table 3.
Next, we undertook a multivariable analysis including the top three predictive variables found in the ROC analysis, specifically PIFR at discharge, frailty score, and CAT at discharge. Three variables were selected to remain within our prespecified power calculation since there were 31 readmissions. Among the three variables, only PIFR remained significantly associated with readmission at 30 days (OR 0.94, 95\% CI 0.91-97, $\mathrm{p}<0.001$ ). Thus, those with lower PIFR values were at higher risk of readmission (Table 3). We assessed the combined predictive ability of these three variables together, which showed an excellent predictive performance (AUC 0.89, CI 0.81 to 0.96, $\mathrm{p}<0.001)$ as presented in Figure 2. 


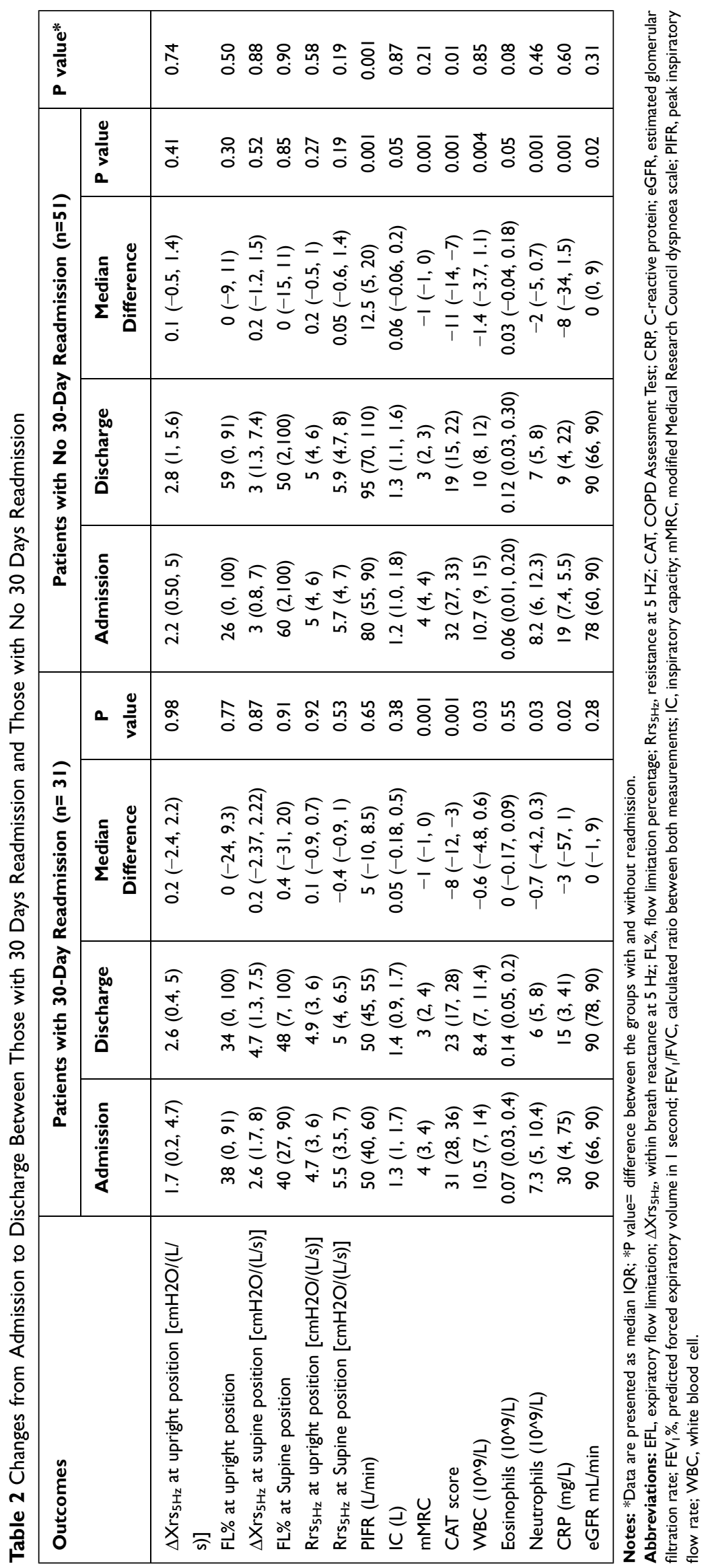


Table 3 Predictors of Readmission Within 30 Days of Index COPD Exacerbation Hospitalisation

\begin{tabular}{|c|c|c|c|c|c|}
\hline Risk Factor & OR & $95 \% \mathrm{Cl}$ & $P$ value & AUC $(95 \% \mathrm{Cl})$ & P value \\
\hline \multicolumn{6}{|l|}{ Univariate analysis } \\
\hline Number of Exacerbations ( $<12$ months) & 1.27 & $1.03-1.60$ & 0.027 & $0.66(0.54-0.78)$ & 0.01 \\
\hline Number of hospitalised exacerbations ( $<12$ months) & 1.39 & $1.05-1.80$ & 0.021 & $0.67(0.55-0.79)$ & 0.008 \\
\hline CAT at discharge & 1.14 & $1.04-1.24$ & 0.004 & $0.68(0.55-0.8 I)$ & 0.006 \\
\hline Frailty Score & 1.72 & $1.32-2.29$ & $<0.001$ & $0.8 \mathrm{I}(0.7 \mathrm{I}-90)$ & $<0.001$ \\
\hline Depression & 1.12 & $1.01-1.24$ & 0.038 & $0.65(0.53-0.77)$ & 0.02 \\
\hline PIFR at admission (L/min) & 0.94 & $0.92-0.97$ & $<0.001$ & $0.77(0.67-0.88)$ & $<0.001$ \\
\hline PIFR at discharge (L/min) & 0.93 & $0.90-0.96$ & $<0.001$ & $0.86(0.78-0.95)$ & $<0.001$ \\
\hline Length of stay (days) & 1.08 & $1.01-1.16$ & 0.034 & $0.64(0.52-0.76)$ & 0.03 \\
\hline Change in PIFR (L/min) & 0.93 & $0.89-0.97$ & 0.001 & $0.66(0.53-0.78)$ & 0.02 \\
\hline Change in CAT & 1.12 & $1.02-1.22$ & 0.019 & $0.76(0.65-0.87)$ & $<0.001$ \\
\hline \multicolumn{6}{|l|}{ Multivariable analysis } \\
\hline Frailty score & 1.31 & $0.96-1.80$ & 0.08 & & \\
\hline PIFR at discharge (L/min) & 0.94 & $0.91-0.97$ & $<0.001$ & & \\
\hline CAT at discharge & 1.01 & $0.91-1.13$ & 0.77 & & \\
\hline
\end{tabular}

Abbreviations: AUC, area under curve; CAT, COPD Assessment Test; FEVI\%, predicted forced expiratory volume in I second; PIFR, peak inspiratory flow rate; OR, odd ratio; $\mathrm{Cl}$, confidence interval.

\section{Sensitivity and Specificity of Predictors with AUC $>0.80$}

According to the ROC analysis, the optimal cut-off for PIFR to predict readmission was $62.5 \mathrm{~L} / \mathrm{min}$ which was $82 \%$ sensitive and $83 \%$ specific. For a specificity of $90 \%$, the cut-off decreased to $54 \mathrm{~L} / \mathrm{min}$ giving a sensitivity of $58 \%$. In contrast, at $90 \%$ sensitivity, a cut of $82.5 \mathrm{~L} / \mathrm{min}$ was $67 \%$ specific. The calculated positive predictive value (PPV) and negative predictive value (NPV) for each cutoff is presented in Table 4. Regarding frailty, the best cutoff score was 10.5 and this was $81 \%$ sensitive and $73 \%$ specific. More details about other cut-off values with their PPV and NPV are reported in Table 4.

\section{Factors Associated with the Readmission Within 90 Days}

Using univariate logistic-regression analysis, we found those with flow limitation in the supine position had the greatest odds of 90-day readmission among all variables (OR 3.02, $95 \%$ CI 1.17-7.83, $\mathrm{p}=0.022$ ), followed by frailty score (OR $1.65,95 \%$ CI $1.27-2.13, \mathrm{p}=0.022$ ). Length of stay was not found to be a significant predictor for 90-day readmission (OR 1.03, 95\% CI 0.96-1.10, $\mathrm{p}=0.96$ (Table 5).

Next, ROC analysis of all the variables in the univariate logistic regression to assess prediction of readmission within 90 days was undertaken. PIFR at discharge had the highest AUC (0.86, CI 0.77 to $0.95, \mathrm{p}<0.001)$, with an excellent ability to predict readmission. Table 5 presents the ROC analysis for predictors of 90-day readmission, which were statistically significant for all variables, except length of stay.

A multivariable analysis to predict 90 days readmission was performed including PIFR at discharge, frailty score, CAT at discharge and exacerbations within past 12 months. Only PIFR at discharge was predictive of 90 -day readmission amongst these variables, (OR 0.95, 95\% CI 0.92-0.97, $\mathrm{p}=0.001$ ). Table 5 shows the multivariable logistic regression for readmission within 90 days. Sensitivity, specificity, PPV and NPV for PIFR were assessed at discharge to predict 90day readmission. A cut off at $72.5 \mathrm{~L} / \mathrm{min}$ had $78 \%$ sensitivity, $88 \%$ specificity and a PPV of $77.5 \%$ indicating good clinical ability to predict readmission (Table 6).

\section{Discussion}

This is the first study to prospectively incorporate simple measures including CAT, PIFR and FOT, together with inflammatory biomarkers and clinical variables to predict 30 and 90-day all-cause readmission following hospitalisation for an exacerbation of COPD. The 30-day and 90day hospital readmission rates in our study were $38 \%$ and $56 \%$, respectively, in keeping with the range reported in a recent systematic review. ${ }^{7}$ We found that previous exacerbations, higher CAT score at discharge, frailty, discharge PIFR and increased length of stay were significantly associated with 30-day readmissions. Furthermore, 90-day readmissions were significantly associated with 


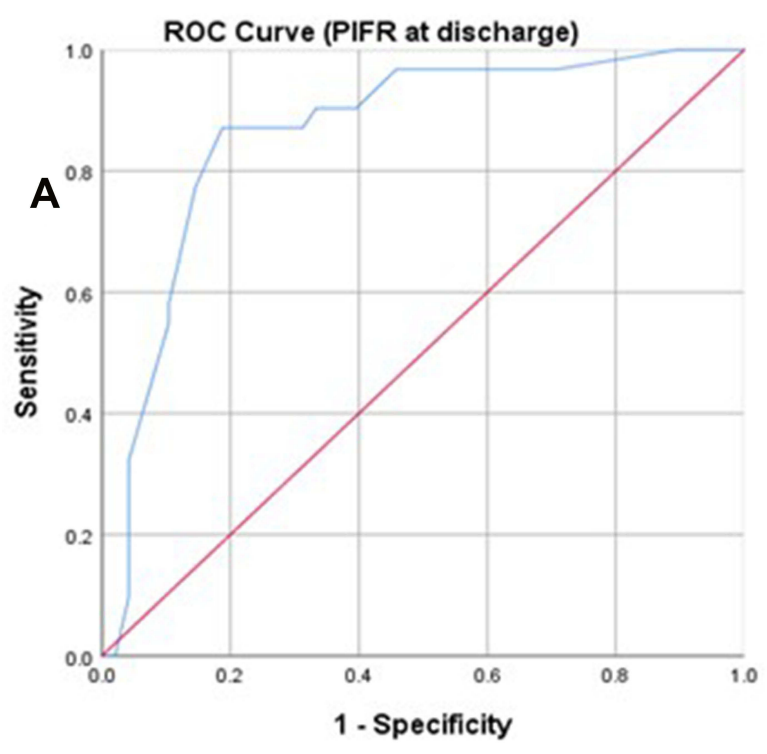

(AUC $0.86,95 \% \mathrm{Cl} 0.78$ to $0.95, \mathrm{p}<0.001$ )

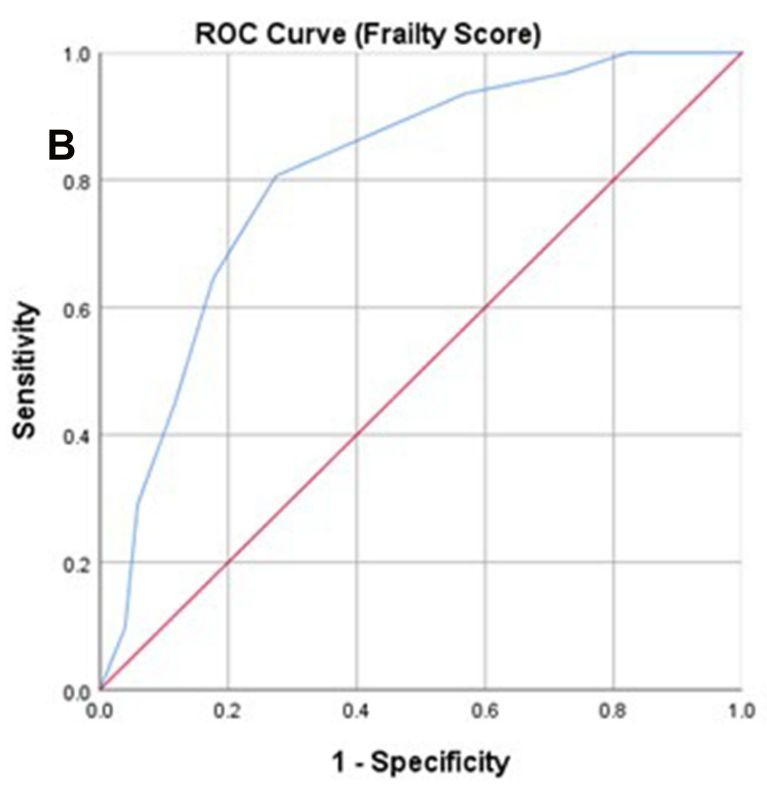

(AUC $0.81,95 \% \mathrm{Cl} 0.71$ to $0.90, \mathrm{p}<0.001$ )

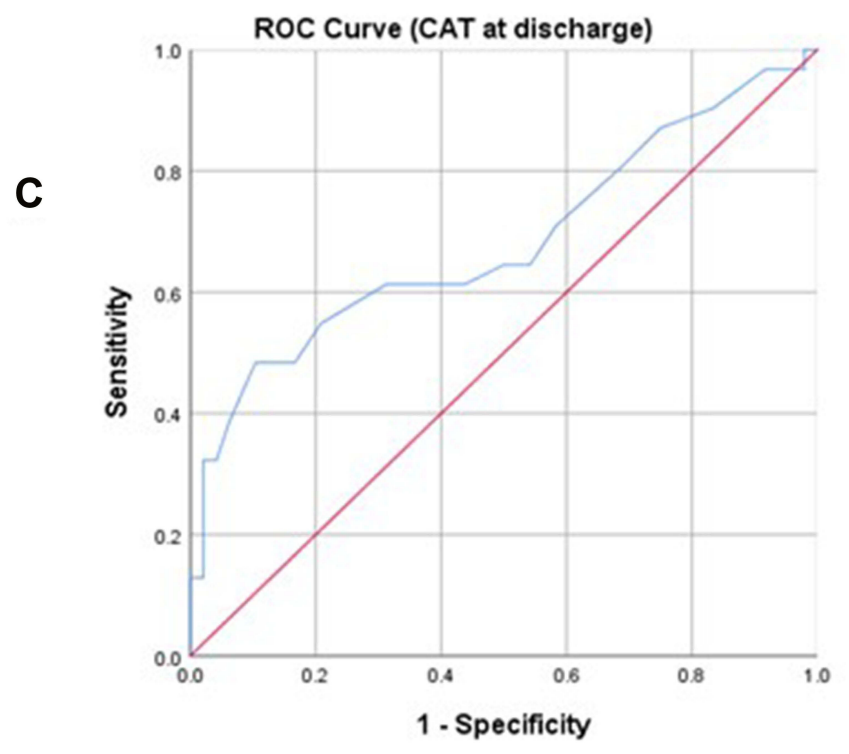

(AUC $0.68,95 \% \mathrm{Cl} 0.55$ to $0.81, p=0.006$ )

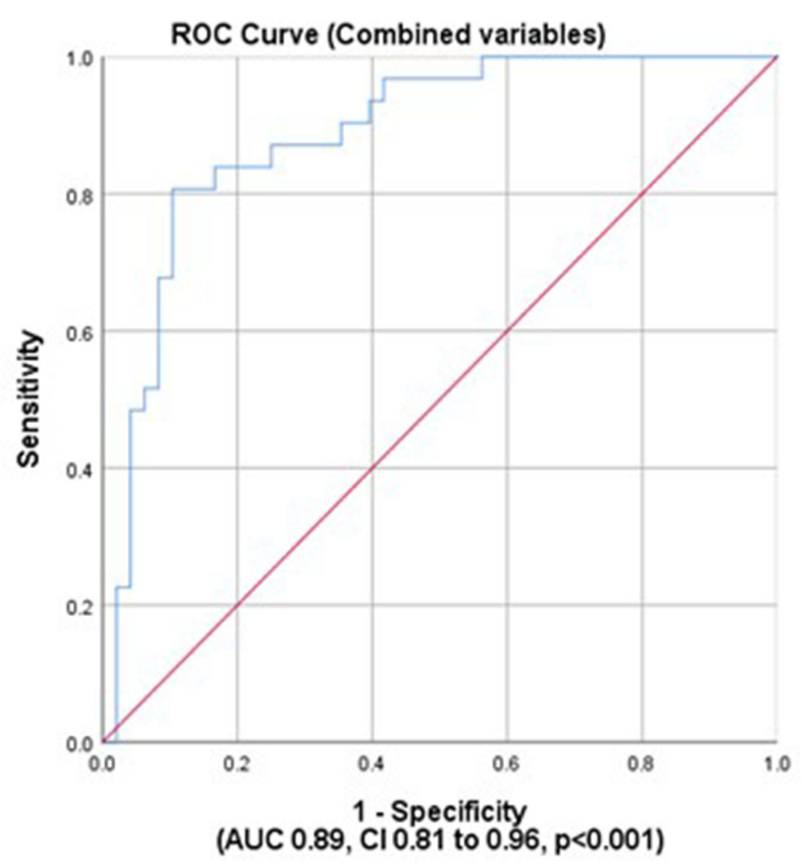

Figure 2 Receiver Operating Characteristic (ROC) curve of predictors for COPD exacerbation readmission within 30 days. (A) ROC of peak inspiratory flow rate (PIFR) at discharge. (B) ROC of Frailty score. (C) ROC of COPD Assessment Test (CAT) score at discharge. (D) ROC of combined variables (PIFR at discharge, Frailty score and CAT score at discharge).

previous exacerbations and hospitalisations, higher CAT score at discharge, frailty, depression, PIFR and EFL in supine position. The best predictive variable in multivariable analysis for both 30- and 90-day COPD readmission was PIFR at discharge.

These data demonstrate that PIFR at discharge can predict both 30- and 90-day readmission risk with an excellent AUC value of 0.86 for both 30- and 90-day readmission. There is little existing literature on the use of PIFR in this situation, and conflicting results. Loh et $\mathrm{al}^{25}$ conducted a retrospective analysis of hospitalised patients and showed that suboptimal PIF was the only variable that predicted days to COPD readmission. However, Sharma et $\mathrm{al}^{26}$ found no association between PIFR and all-cause readmission over six months. We report, for the first time, the prevalence of suboptimal PIFR at admission and at discharge during COPD exacerbation, and therefore unlike others we can examine risk in those with improving versus no change in PIFR over 
Table 4 Sensitivity, Specificity, PPV and NPV of the PIFR and Frailty to Predict 30 Days Readmission Following COPD Exacerbation $(\mathrm{AUC}>0.80)$

\begin{tabular}{|c|c|c|c|c|c|}
\hline Predictor & Cut-Off & Sensitivity & Specificity & PPV & NPV \\
\hline \multirow[t]{3}{*}{ PIFR at discharge (L/min) } & 62.5 & $82 \%$ & $83 \%$ & $70 \%$ & $91 \%$ \\
\hline & 54 & $58 \%$ & $90 \%$ & $78 \%$ & $77 \%$ \\
\hline & 82.5 & $90 \%$ & $67 \%$ & $64 \%$ & $91 \%$ \\
\hline \multirow[t]{3}{*}{ Frailty Score } & 10.5 & $81 \%$ & $73 \%$ & $46 \%$ & $70 \%$ \\
\hline & 12.5 & $45 \%$ & $90 \%$ & $50 \%$ & $66 \%$ \\
\hline & 9.5 & $93 \%$ & $44 \%$ & $45 \%$ & $79 \%$ \\
\hline
\end{tabular}

Abbreviations: PIFR, peak inspiratory flow rate; PPV, positive predictive value; NPV, negative predictive value.

Table 5 Predictors of Readmission Within 90 Days of Index Hospitalisation

\begin{tabular}{|c|c|c|c|c|c|}
\hline Risk Factor & OR & $95 \% \mathrm{Cl}$ & $\mathbf{P}$ value & AUC $(95 \% \mathrm{Cl})$ & $P$ value \\
\hline \multicolumn{6}{|l|}{ Univariate analysis } \\
\hline Number of Exacerbations ( $<12$ months) & 1.44 & I.II-I.87 & 0.005 & $0.72(0.6 \mathrm{I}-0.84)$ & 0.001 \\
\hline Number of hospitalised exacerbations ( $<12$ months) & 1.57 & $1.13-2.18$ & 0.007 & $0.7 \mathrm{I}(0.59-0.83)$ & 0.001 \\
\hline CAT at discharge & 1.16 & $1.06-1.28$ & 0.002 & $0.72(0.61-0.83)$ & 0.001 \\
\hline Frailty Score & 1.65 & $1.27-2.13$ & $<0.001$ & $0.78(0.67-0.88)$ & $<0.001$ \\
\hline Depression & 1.14 & $1.02-1.27$ & 0.013 & $0.67(0.55-0.79)$ & 0.007 \\
\hline PIFR at admission (L/min) & 0.94 & $0.92-0.97$ & $<0.00$ I & $0.81(0.7 I-0.90)$ & $<0.001$ \\
\hline PIFR at discharge (L/min) & 0.93 & $0.91-0.96$ & $<0.00$ I & $0.86(0.77-0.95)$ & $<0.001$ \\
\hline Length of stay (days) & 1.03 & $0.96-1.10$ & 0.37 & $0.55(0.43-0.68)$ & 0.38 \\
\hline Change in PIFR (L/min) & 0.94 & $0.91-0.98$ & 0.002 & $0.73(0.60-0.84)$ & 0.001 \\
\hline Change in CAT & 1.05 & $0.96-1.16$ & 0.25 & $0.76(0.65-0.87)$ & $<0.001$ \\
\hline Flow Limited in supine position at discharge (Yes vs No) & 3.02 & I. $17-7.83$ & 0.022 & $0.63(0.5 \mathrm{I}-0.76)$ & 0.04 \\
\hline BMI (kg/m2) & 0.94 & $0.89-0.99$ & 0.031 & $0.65(0.53-0.77)$ & 0.02 \\
\hline \multicolumn{6}{|l|}{ Multivariable analysis } \\
\hline Frailty score & 1.17 & $0.85-1.6 \mathrm{I}$ & 0.32 & & \\
\hline PIFR at discharge (L/min) & 0.95 & $0.92-97$ & 0.001 & & \\
\hline CAT at discharge & 1.05 & $0.92-1.19$ & 0.44 & & \\
\hline Exacerbations ( $<12$ months) & 1.36 & $0.95-1.95$ & 0.76 & & \\
\hline
\end{tabular}

Abbreviations: AUC, area under curve; CAT, COPD Assessment Test; FEVI\%, predicted forced expiratory volume in I second; PIFR, peak inspiratory flow rate; OR, odd ratio; $\mathrm{Cl}$, confidence interval.

Table 6 Sensitivity, Specificity, PPV and NPV of the Best Predictor for 90-Day Readmission

\begin{tabular}{|l|l|l|l|l|l|}
\hline Predictor & Cut-Off & Sensitivity & Specificity & PPV & NPV \\
\hline PIFR at discharge (L/min) & 72.5 & $78 \%$ & $88 \%$ & $77.5 \%$ & $75 \%$ \\
& 92.5 & $89 \%$ & $67 \%$ & $76 \%$ & $77 \%$ \\
& 77.5 & $78 \%$ & $92 \%$ & $65 \%$ \\
\hline
\end{tabular}

Abbreviations: PIFR, peak inspiratory flow rate; PPV, positive predictive value; NPV, negative predictive value.

this period. Our finding that the prevalence of sub-optimal PIFR during hospitalisation was $40 \%$, which is greater than the $31 \%$ prevalence reported by Sharma. ${ }^{26}$ In contrast, Loh et al $2017^{25}$ found a higher prevalence of sub-optimal PIFR at $52 \%$. However, this study used $60 \mathrm{~L} / \mathrm{min}$ or less as a cutoff to define sup-optimal PIFR, dissimilar to us and others which used less than $60 \mathrm{~L} / \mathrm{min}$ as a threshold. ${ }^{26}$ PIFR is clinically important in assessing a patient's ability to create an appropriate inspiratory flow rate and therefore whether patients can sufficiently inhale from a DPI. ${ }^{26}$ PIFR is simple and cheap to measure and could be widely adopted in clinical practice. 
We identified several other factors associated with an increased risk of readmission. Consistent with existing literature, we found that previous COPD exacerbations and hospitalisations were significantly associated with allcause readmission. ${ }^{7,27}$ Hospitalisations due to COPD exacerbations can lead to significant economic and clinical burden, ${ }^{28}$ which can be 60 times more expensive than mild and moderate exacerbations managed by community services. ${ }^{29}$ Such frequent severe exacerbations are linked with increased mortality. ${ }^{30}$ Thus, early detection of exacerbation symptoms and timely management may reduce the likelihood of hospitalisation and ultimately readmission.

Discharge assessment is the key to assessing and mitigating readmission risk. We found that higher CAT score at discharge was associated with readmission, in which those who get readmitted had greater CAT scores at discharge compared to those with no readmission. This indicates that those patients who are readmitted were more symptomatic at discharge. This may be because they have more severe symptoms in the stable state, or that their acute symptoms had not yet recovered. A potential explanation of this finding would be that these exacerbations were not fully treated, and that they might take longer time to recover. ${ }^{31}$

To our knowledge, this is the first study to report frailty defined by the REFS as an independent risk factor for 30-day readmission following exacerbation of COPD. A study conducted in Spain found frailty as defined by the REFS to be a risk factor for 90 day COPD readmission, but this did not report shorter 30-day outcomes. ${ }^{32}$ The authors reported that those with higher frailty scores were five times more likely to get readmitted compared to non-frail patients. Assessing patients during hospitalisation using multidimensional frailty tool such as REFS may be beneficial to stratify patients who are at higher readmission risk. This would facilitate personalised disease management, aiming to improve the outcomes in these vulnerable patients. Depression was associated with 90-day readmission in our study. This finding broadly supports the work of other studies in this area linking depression with COPD readmission. ${ }^{7,33}$ Despite the high prevalence of depression in COPD patients, ${ }^{34}$ thus far, there is no specific evidence to support the efficiency of antidepressants in reducing read${\text { mission } \text { risk. }^{35}}^{35}$

Increased length of stay was found to be a significant risk factor for readmission within 30 days but not 90 days. This finding is consistent with other studies included in our recent systematic review. ${ }^{7}$ Thus, length of stay can be used as a potential indicator for patients who may benefit from community support and earlier follow-up following initial discharge.

No previous studies have tested whether using FOT with objective measurements of resting lung function during hospitalisation can predict readmission following a COPD exacerbation. Expiratory Flow Limitation as measured by $\Delta \mathrm{Xrs}_{5 \mathrm{~Hz}}$ in the supine position at discharge was found to be a significant predictor for 90-day readmission. Thus, using FOT during hospitalisations may support clinicians in detection of patients at higher risk of readmission. Walker et $\mathrm{al}^{36}{ }^{36}$ reported that using FOT to measure lung function in COPD patients at the time of exacerbation was practical, well tolerated, and acceptable, allowing it to be incorporated into clinical services.

Our study findings have important clinical implications. It emphasises the importance of discharge assessments in predicting COPD readmission risk. Clinicians should measure PIFR at discharge to guide COPD treatment options, which may reduce readmission risk. In addition to the assessment of symptoms using CAT, FOT could be used as a complimentary option to categorise those patients with EFL at discharge who may benefit from additional therapy and timely follow-up, aiming to mitigate symptoms and unresolved EFL, and reduce readmission. Identifying patients with severe frailty would facilitate potential rehabilitation programmes following discharge that could decrease readmission, such as postexacerbation pulmonary rehabilitation.

This study has strengths and limitations. We prospectively followed patients for 30 and 90 days to determine potential predictors of readmission that would support optimisation of care prior to discharge by highlighting factors that can be modified. Another strength is the comprehensive assessment we conducted at admission and discharge that included objective measures such as spirometry, FOT, PIFR and inflammatory biomarkers. However, we are limited by not having a separate validation cohort and conducting the study in one site, which therefore requires independent confirmation of our results to confirm the generalisability of our findings. Our follow up was complete at 90 days but it would have been useful to look at longer term outcomes such as readmission within 12 months and mortality, but this was beyond the scope of the present study.

\section{Conclusion}

Our study shows that previous exacerbations, higher CAT score at discharge, frailty, reduced PIFR at discharge and increased length of stay were significant predictors for 30day readmission following exacerbation of COPD. EFL (measured by $\Delta \mathrm{Xrs}_{5 \mathrm{~Hz}}$ ) in the supine position was 
significantly associated with 90-day readmission. This finding supports clinicians in identifying COPD patients at higher readmission risk to improve their outcomes by delivering effective personalised interventions.

\section{Data Sharing Statement}

The datasets used and/or analysed during the current study are available from the corresponding author on reasonable request.

\section{Funding}

This trial was conducted as part of a $\mathrm{PhD}$ funded in association with Prince Sultan Military College of Health Sciences (PSMCHS) (Dammam, Saudi Arabia) through the Saudi Arabian Cultural Bureau (London, UK).

\section{Disclosure}

Professor John R Hurst report grants, personal fees from Pharmaceutical companies that make medicines to treat COPD, outside the submitted work. The authors report no other conflicts of interest in this work.

\section{References}

1. Oliveira CC, Lee AL, McGinley J, et al. Balance and falls in acute exacerbation of chronic obstructive pulmonary disease: a prospective study. COPD. 2017;14(5):518-525. doi:10.1080/15412555.2017.13 42232

2. Ho TW, Tsai YJ, Ruan SY, Huang CT, Lai F, Yu CJ. In-hospital and one-year mortality and their predictors in patients hospitalized for first-ever chronic obstructive pulmonary disease exacerbations: a nationwide population-based study. PLoS One. 2014;9(12): e114866. doi:10.1371/journal.pone.0114866

3. Soler-Cataluña JJ, Martínez-García MA, Román Sánchez P, Salcedo E, Navarro M, Ochando R. Severe acute exacerbations and mortality in patients with chronic obstructive pulmonary disease. Thorax. 2005;60 (11):925-931.

4. Jencks SF, Williams MV, Coleman EA. Rehospitalizations among patients in the Medicare fee-for-service program. $N$ Engl $J$ Med. 2009;360(14):1418-1428. doi:10.1056/NEJMsa0803563

5. Iacobucci G. Hospital readmissions for COPD in England are rising, audit shows. BMJ. 2017;356:j557. doi:10.1136/bmj.j557

6. Stone RAH-BJ, Lowe D, McMillan V, et al. COPD: Who Cares When It Matters Most? National Chronic Obstructive Pulmonary Disease (COPD) Audit Programme: Outcomes from the Clinical Audit of COPD Exacerbations Admitted to Acute Units in England 2014. National Supplementary Report. London: RCP; 2017. Available from: www.rcplondon.ac.uk/copd-outcomesreport2014. Accessed September 30, 2021.

7. Alqahtani JS, Njoku CM, Bereznicki B, et al. Risk factors for all-cause hospital readmission following exacerbation of COPD: a systematic review and meta-analysis. Eur Respir Rev. 2020;29(156):190166. doi:10.1183/16000617.0166-2019

8. Hartl S, Lopez-Campos JL, Pozo-Rodriguez F, et al. Risk of death and readmission of hospital-admitted COPD exacerbations: European COPD audit. Eur Respir J. 2016;47(1):113-121. doi:10.1183/13993 003.01391-2014
9. Alqahtani JS, Aquilina J, Bafadhel M, et al. Research priorities for exacerbations of COPD. Lancet Respir Med. 2021;9(8):824-826. doi:10.1016/S2213-2600(21)00227-7

10. Myers LC, Faridi MK, Hasegawa K, Hanania NA, Camargo CA. The hospital readmissions reduction program and readmissions for chronic obstructive pulmonary disease, 2006-2015. Ann Am Thorac Soc. 2019;17(4):450-456. doi:10.1513/AnnalsATS.201909-672OC

11. Press VG, Au DH, Bourbeau J, et al. Reducing chronic obstructive pulmonary disease hospital readmissions. An Official American Thoracic Society Workshop Report. Ann Am Thorac Soc. 2019;16 (2):161-170. doi:10.1513/AnnalsATS.201811-755WS

12. Nuñez A, Miravitlles M. Preventing readmissions of COPD patients: more prospective studies are needed. Eur Respir Rev. 2020;29 (156):200097. doi:10.1183/16000617.0097-2020

13. Alqahtani J Mechanisms of COPD exacerbation recurrence; 2018. Available from: https://clinicaltrials.gov/ct2/show/NCT04024735. Accessed August 13, 2020.

14. Bestall J, Paul E, Garrod R, Garnham R, Jones P, Wedzicha JJT. Usefulness of the Medical Research Council (MRC) dyspnoea scale as a measure of disability in patients with chronic obstructive pulmonary disease. Thorax. 1999;54(7):581-586.

15. Jones PW, Harding G, Berry P, Wiklund I, Chen WH, Kline Leidy N. Development and first validation of the COPD assessment test. Eur Respir J. 2009;34(3):648. doi:10.1183/09031936.00102509

16. Zigmond AS, Snaith RP. The hospital anxiety and depression scale. Acta Psychiatrica Scandinavica. 1983;67(6):361-370.

17. Hilmer SN, Perera V, Mitchell S, et al. The assessment of frailty in older people in acute care. Austr J Ageing. 2009;28(4):182-188.

18. Miller MR, Hankinson J, Brusasco V, et al. Standardisation of spirometry. Eur Respir J. 2005;26(2):319-338. doi:10.1183/ 09031936.05.00034805

19. Oostveen E, MacLeod D, Lorino H, et al. The forced oscillation technique in clinical practice: methodology, recommendations and future developments. Eur Respir J. 2003;22(6):1026. doi:10.1183/ 09031936.03.00089403

20. Dellacà RL, Santus $\mathrm{P}$, Aliverti $\mathrm{A}$, et al. Detection of expiratory flow limitation in COPD using the forced oscillation technique. Eur Respir J. 2004;23(2):232. doi:10.1183/09031936.04.00046804

21. Broeders ME, Molema J, Vermue NA, Folgering HT. In check dial: accuracy for Diskus and Turbuhaler. Int J Pharm. 2003;252(12):275-280. doi:10.1016/S0378-5173(02)00650-6

22. Chrystyn H. Is inhalation rate important for a dry powder inhaler? Using the in-check dial to identify these rates. Respir Med. 2003;97 (2):181-187. doi:10.1053/rmed.2003.1351

23. Peduzzi P, Concato J, Feinstein AR, Holford TR. Importance of events per independent variable in proportional hazards regression analysis. II. Accuracy and precision of regression estimates. $J$ Clin Epidemiol. 1995;48(12):1503-1510. doi:10.1016/0895-4356(95)00048-8

24. Peduzzi P, Concato J, Kemper E, Holford TR, Feinstein AR. A simulation study of the number of events per variable in logistic regression analysis. J Clin Epidemiol. 1996;49(12):1373-1379. doi:10.1016/S0895-4356(96)00236-3

25. Loh CH, Peters SP, Lovings TM, Ohar JA. Suboptimal inspiratory flow rates are associated with chronic obstructive pulmonary disease and all-cause readmissions. Ann Am Thorac Soc. 2017;14 (8):1305-1311. doi:10.1513/AnnalsATS.201611-903OC

26. Sharma G, Mahler DA, Mayorga VM, Deering KL, Harshaw O, Ganapathy V. Prevalence of low peak inspiratory flow rate at discharge in patients hospitalized for COPD exacerbation. Chronic Obstruct Pul Dis. 2017;4(3):217-224. doi:10.15326/jcopdf.4.3.2017.0183

27. Njoku CM, Alqahtani JS, Wimmer BC, et al. Risk factors and associated outcomes of hospital readmission in COPD: a systematic review. Respir Med. 2020;173:105988. doi:10.1016/j.rmed.2020.105988

28. Wedzicha JA, Wilkinson T. Impact of chronic obstructive pulmonary disease exacerbations on patients and payers. Proc Am Thorac Soc. 2006;3(3):218-221. doi:10.1513/pats.200510-114SF 
29. Andersson F, Borg S, Jansson SA, et al. The costs of exacerbations in chronic obstructive pulmonary disease (COPD). Respir Med. 2002;96 (9):700-708. doi:10.1053/rmed.2002.1334

30. Soler-Cataluña JJ, Martínez-García MÁ, Román Sánchez P, Salcedo E, Navarro M, Ochando R. Severe acute exacerbations and mortality in patients with chronic obstructive pulmonary disease. Thorax. 2005;60(11):925.

31. Wilkinson TMA, Donaldson GC, Hurst JR, Seemungal TAR, Wedzicha JA. Early therapy improves outcomes of exacerbations of chronic obstructive pulmonary disease. Am J Respir Crit Care Med. 2004;169(12):1298-1303. doi:10.1164/rccm.200310-1443OC

32. Bernabeu-Mora R, García-Guillamón G, Valera-Novella E, GiménezGiménez LM, Escolar-Reina P, Medina-Mirapeix F. Frailty is a predictive factor of readmission within 90 days of hospitalization for acute exacerbations of chronic obstructive pulmonary disease: a longitudinal study. Ther Adv Respir Dis. 2017;11(10):383-392. doi:10.1177/1753465817726314
33. Iyer AS, Bhatt SP, Garner JJ, et al. Depression is associated with readmission for acute exacerbation of chronic obstructive pulmonary disease. Ann Am Thorac Soc. 2016;13(2):197-203.

34. Light RW, Merrill EJ, Despars JA, Gordon GH, Mutalipassi LR. Prevalence of depression and anxiety in patients with COPD. Relationship to functional capacity. Chest. 1985;87(1):35-38. doi:10. 1378/chest.87.1.35

35. Usmani ZA, Carson KV, Cheng JN, Esterman AJ, Smith BJ. Pharmacological interventions for the treatment of anxiety disorders in chronic obstructive pulmonary disease. Cochrane Database Syst Rev. 2011;11:Cd008483.

36. Walker PP, Pompilio PP, Zanaboni P, et al. Telemonitoring in chronic obstructive pulmonary disease (chromed) a randomized clinical trial. Am J Respir Crit Care Med. 2018;198(5):620-628. doi:10.1164/ rccm.201712-2404OC

\section{Publish your work in this journal}

The International Journal of COPD is an international, peer-reviewed journal of therapeutics and pharmacology focusing on concise rapid reporting of clinical studies and reviews in COPD. Special focus is given to the pathophysiological processes underlying the disease, intervention programs, patient focused education, and self management protocols. This journal is indexed on PubMed Central, MedLine and CAS. The manuscript management system is completely online and includes a very quick and fair peer-review system, which is all easy to use. Visit http://www.dovepress.com/testimonials.php to read real quotes from published authors. 